\title{
THE IMPACT OF MALARIA DISEASE ON PRODUCTIVITY OF RURAL FARMERS IN OSUN STATE, NIGERIA.
}

\author{
Ogunniyi Adebayo $^{(1)}$, Kehinde Olagunju ${ }^{(2)}$, Adewuyi S. A ${ }^{(3)}$ \\ ${ }^{1}$ MSc Student, Szent Istvan University, Faculty of Economics and Social Sciences, Gödöllő, \\ Hungary \\ ${ }^{2}$ MSc Student, Department of Agricultural Economics, University of Ibadan, Ibadan, Nigeria \\ ${ }^{3}$ Associate Professor, Department of Agricultural Economics \& Farm Management, \\ University of Agriculture, Abeokuta, Ogun State, Nigeria \\ E-mail: bayogunniyiconsult@gmail.com; olagunjukehindeoluseyi@gmail.com
}

\begin{abstract}
In developing countries, the impact of malaria on human health, productivity and human development is well profound. It possesses serious challenge to the survival of several vulnerable poor, whose livelihood depends solely on agriculture. This study was carried out to examine the impact of malaria on the productivity of arable crop farmers and further estimate the cost implication of malaria (direct and Indirect) in rural Nigeria. Data were collected from a random sample of 91 crop farmers through the use of a well- structured questionnaire. The data were analyzed using descriptive statistics and multiple linear regression. The mean age of the crop farmers was 48 years with only $87.9 \%$ percent headed by males. The household heads are largely had primary education. Specifically malaria prevalence, household size, farming experience and cost of malaria treatment were significant factors that influenced crop productivity in the study area. It recommended that public enlightenment under the aegis of the "Roll Back Malaria Campaign" should be intensified and treated mosquito bed nets should be provided at subsidized rates to arable crop farmers. Farmers on their part should keep clean environment. Due regard should be given to environmental sanitation in the rural farming communities in the state.
\end{abstract}

Keywords: Malaria, Productivity, Rural, Farmers, Nigeria JEL classification: Q12,Q15

\section{Introduction}

Malaria and agriculture are intimately related (Oluwatayo, 2014) and tends to have causal relationship, this is because agricultural environments provide suitable conditions for breeding of disease vector which causes malaria in human beings. i.e health affects agriculture and agriculture affects health. The global impact of malaria on human health, productivity, and general well-being is profound, and Africa has been particularly hard hit (Kwadwo AsensoOkyere et al, 2011). The study of Alaba and Alaba, (2010) also revealed that Malaria is one of the greatest threats facing development in Africa today. It attacks an individual on average of four times in a year with an average of 10 to 14 days of incapacitation. Thus, the possibility of adversely affecting productivity with or without frequency of occurrence cannot be over emphasized. In 2006, more than 90 percent of deaths from malaria occurred in Africa, where 45 of the 53 countries are endemic for the disease (WHO, 2011). Malaria costs Africa more than USD12 billion annually, and it slows economic growth in African countries by as much as 1.3 percent per year (WHO, 2010), especially in Nigeria where the improvement of food security - like the growth of food production - is an issue of core importance (Neszmélyi,2014). 
Children and women (particularly pregnant women) in Africa are most vulnerable to malaria attacks. The potential impact of malaria for women engaged in agriculture, especially food production, can be substantial. Women perform nearly all the tasks associated with subsistence food production in Africa. They account for about 70 percent of agricultural workers and 60 to 80 percent of those producing food crops for household consumption and sale, and they also raise and market livestock (Todaro, 2000; FAO 2010). Since the majority of the continent's population is rural, the effects of the disease on agriculture, health, and development are widespread.

In Nigeria, the direct and indirect costs of malaria exceeded US \$2 billion in 1997 and this figure is likely to increase every year (Alaba and Alaba, 2010). To be specific, this is the cost borne by a household of poor smallholder farmers for treatment of a single disease. Removing malaria as a constraint could free resources for household productivity and local development (Kwadwo Asenso-Okyere et al, 2011). There are various channels by which malaria impedes development of a nation, without the exception of Osun state in Nigeria, including effects on fertility, population growth, saving and investment, worker productivity, absenteeism, premature mortality and medical costs (Sachs and Malaney, 2010). Also, Eyo et al. (2006) reported that farmers' health status has a significant effect on their capacity to increase output, otherwise ill health could impact negatively on the number of hours spent on farm and amount of income earned. Health risk and particularly malaria has some debilitating effects on the output and income through cost of health care, labour man days lost to malaria medication and physical weakness. Malaria leads to loss of agricultural labour due to illness and death, wastage of family members' time and energy in caring for malaria patients and grieving for people killed by malaria. Malaria also results into loss of agricultural knowledge and skills especially if it kills an experienced farmer (Oluwatayo, 2014). The production of food from arable crops is vital to the survival of human and other forms of life. They provide man's foods requirement for growth, good health and increased productivity. Large quantities of food items are obtained from arable crops enterprises in Nigeria especially staple food crops such as maize, rice cassava, yams millet, sorghum and cowpea upon which most Nigeria depend on survival.

Malaria, is not only a health problem, it is also an economic problem. Malaria at the household level affects productivity of the people and their assets acquisition capacity. Households also frequently spend substantial share of their income and time on malaria prevention and treatment as well as an effort to control mosquitoes (Coluzzi, 1999). The cost of prevention and treatments consumes scarce crop farmer's resources. Also as some household members spend their productive time caring for those under malaria attack, they themselves in turn seek rescue from the onslaught of the disease (Mills, 1998). Malaria therefore has a direct impact on households' income, wealth, labour productivity and labour market participation of both the sick and the caregivers. In terms of resource loss, households spend between \$2 and \$25 on malaria treatment and between $\$ 20$ and $\$ 15$ on prevention each month (Mills, 1998). As much as 13 percent of total small farming households expenditure in Nigeria is currently being used in treating malaria, while many are simply too poor to pay for adequate prevention and treatment of the disease (WHO, 2011). The loss to households may however be greater with the current trend in malaria resistance to traditional first-line drugs. Such loss has serious implication for poor household who are already malnourished, who live under pitiable condition and who constitute over 65 percent of the nation's population. Calculating the loss of productivity or productive potential resulting from sickness involves the application of some consensual economic principles.

Earnings, which include wages, salaries and other remunerations other than transfers have been theoretically and generally accepted as an appropriate measure of workers' productivity. Some 
pioneers on the empirical assessment of the impact of health status on productivity did so by relating health status to earnings and other income-generating potentials (Ajani and Ashagidigbi, 2008).

Given the severe impacts of malaria in Osun state Nigeria, a key development challenge is to examine the linkages between malaria and agriculture. Agriculture has for many centuries played a pivotal role in economic growth worldwide, particularly Nigeria where agricultural production and diversification of economy are key to structural change of the national economy (Neszmélyi, 2014). Presently, there is widespread recognition among African leaders, international organizations, and the donor community that improving the productivity and income-generating capacity of agriculture is essential in poverty reduction and economic growth (Kwadwo Asenso-Okyere et al, 2011). Though, studies on the impact of malaria on farming households have been examined but to the best of researcher's knowledge, the case of arable crop farmers have not been sharply considered. Furthermore, Osun state seems to have been neglected by researchers in examining the possible impact of this endemic disease. Therefore, to foster progress toward agriculture-led food security and economic growth, developing countries like Nigeria need to pay closer attention to the development of human capital through investments in education and training, health and sanitation, and food and nutrition to enhance arable crop productivity. Thus, this study seeks to broadly examine the impact of malaria on arable crop farmer's productivity in Osun State, Nigeria. The specific objective is:

- to estimate cost implication of malaria in the study area

- to determine the effect of malaria on the productivity level of arable crop farmers in the study area.

\section{Material and methods}

\section{The study area}

This study area is Osun State of Nigeria. The state covers an area of approximately 8,882 square kilometers $\left(\mathrm{km}^{2}\right)$ with population of 3,423,535 million from the 2006 census. Osun State has over 200 towns, villages, and settlements most of whose dwellers are farmers. The estimated land area of Osun State of about $8,882.55 \mathrm{~km}^{2}$ is mostly cultivated with crops by about 256,000 farm families. The average relative humidity of 75.6 percent and a temperature of $25^{\circ} \mathrm{C}$ and $32^{\circ} \mathrm{C}$ are experienced in the state. The annual average rainfall ranges between $1200 \mathrm{~mm}$ and $1,850 \mathrm{~mm}$. The rainy season is bimodal with one dry season of less than 5 months. The distribution patterns are such that permits early maturing crops such as maize to be grown twice a year. They major producer of arable crops in Southwest Nigeria.

\section{Method of data collection}

Structured and systematically drawn questionnaires as well as personal interviews were the data collection instruments. Data were collected on the socio-economic characteristics and also on malaria incidence as it affects rural household's health and their agricultural productivity. Simple random technique was used in the course of the research in which 91 respondents were selected. 


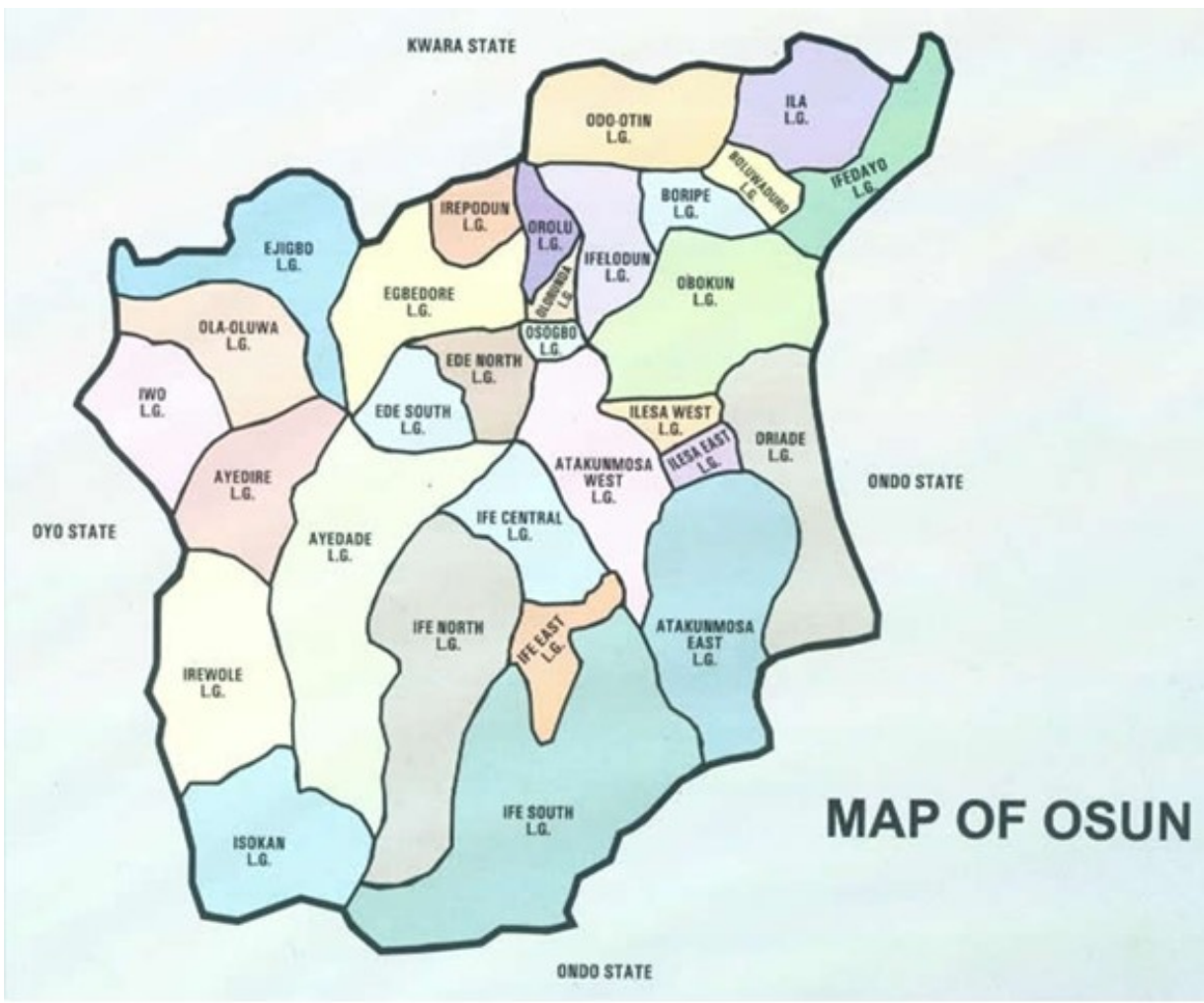

Source: Google Earth, 2015

Figure 1: Map of Osun State, Nigeria

\section{Analytical tools}

Descriptive analysis was used the socio-economic characteristic and to estimate the cost implication of the crop farmers in the study area which include the use of mean, percentage and frequency table. The methods of analysis employed include descriptive statistics and regression analysis to estimate the impact of malaria prevalence on crop productivity of rural farmers in the study area.

\section{Regression Analysis of effects of Malaria on agricultural productivity}

Regression analysis was used to analyse the effect of malaria on crop productivity index(Y). The empirical model specifies crop productivity as the dependent variable $(\mathrm{Y})$ and independent variables which include the malaria prevalence, age, Household size, cost of malaria treatment and transportation cost on malaria treatment. 
This can be implicitly and explicitly be expressed as:

$$
\begin{aligned}
& \text { Implicitly; } Y=f\left(X_{1}, X_{2}, X_{3}, X_{4}, X_{5}, X_{6}, e\right) \\
& \text { Explicitly: } \mathrm{Y}=X_{1}+X_{2}+X_{3}+X_{4}+X_{5}+X_{6}+e \\
& \mathrm{Y}=\text { total productivity index }=\frac{\text { value of output }}{\text { total cost of } \text { input }} \\
& \mathrm{X}_{1}=\text { Malaria prevalence } \\
& \mathrm{X}_{2}=\text { Cost of malaria treatment (naira) Age of the respondent (years) } \\
& \mathrm{X}_{3}=\text { Household size (number of people) } \\
& \mathrm{X}_{4}=\text { Farm size (hectares) } \\
& \mathrm{X}_{5}=\text { Farming experience (years) } \\
& \mathrm{X}_{6}=\text { Age } \\
& \mathrm{e}=\text { Error term }
\end{aligned}
$$

\section{Results and discussion}

\section{Farming household characteristics}

The result shown in Table 1 depicts the fact that a high proportion of the respondents were males $(87.9 \%)$, thereby re-validating the age-long dominance of men in agriculture in which all the respondents $(100 \%)$ are married. The study reveals that considerable young adults are involved in arable crop farming in the study area. Thus, more than half the respondents $(51.6 \%)$ were between the age of 30 and 45 years and the mean age of the farmers was 48.19 years. This implies that they are in their active productive age in which their farm productivity should be relatively high, given a healthy living condition devoid of malaria and other productivity diminishing problems. A large number of the respondents $(48.7 \%)$ have household size between 9 and12. The mean household size of the study sample was 8 . This may have positive implication on the on the strength of farm labour supply as their will be more family labour for farm work which can enhance productivity. The educational level of the respondents shows that majority $(52.7 \%)$ have primary education while $23.1 \%$ were below primary level. Farmers with higher levels of education are likely to be more efficient in the use of inputs than their counterpart with little or no education because education and literacy help to eradicate ignorance and promote adoption of innovation. The study shows that more than one-third (37.4) of the respondents has arable crop farming experience of between 11-20 years. This is followed by 28.6 percent of the population with 21-30 years' experience. The mean farm size was 0.97 hectares, signifying that on the average, arable crop farmers in the study were small scale farm holders. This is the likely due to the problem of land fragmentation as a result of inheritance which is quite common in the Southwestern part of the country. 
Table 1: Respondents' Distribution by Socioeconomic Characteristics

\begin{tabular}{|c|c|c|c|}
\hline $\begin{array}{l}\text { Socioeconomic } \\
\text { variables }\end{array}$ & Frequency & Percentage & $\begin{array}{ll}\begin{array}{l}\text { Mean } \\
\text { deviation) }\end{array} & \text { (Standard } \\
\end{array}$ \\
\hline \multicolumn{4}{|l|}{ Gender } \\
\hline Male & 80 & 87.9 & \\
\hline Female & 11 & 12.1 & \\
\hline \multicolumn{4}{|l|}{ Marital status } \\
\hline Married & 91 & 100.0 & \\
\hline \multicolumn{4}{|l|}{ Age } \\
\hline$<30$ & 8 & 8.8 & \multirow[t]{4}{*}{$48(2.5)$} \\
\hline $30-45$ & 47 & 51.6 & \\
\hline $46-60$ & 24 & 26.4 & \\
\hline$>60$ & 12 & 13.2 & \\
\hline \multicolumn{4}{|l|}{ Household size } \\
\hline $1-4$ & 11 & 12.1 & \multirow[t]{4}{*}{$8(3.8)$} \\
\hline $5-8$ & 35 & 38.5 & \\
\hline $9-12$ & 37 & 40.7 & \\
\hline$>12$ & 8 & 8.8 & \\
\hline \multicolumn{4}{|l|}{ Educational status } \\
\hline No formal education & 21 & 23.1 & \\
\hline Primary & 48 & 52.7 & \\
\hline Secondary & 17 & 18.7 & \\
\hline Tertiary & 5 & 5.5 & \\
\hline \multicolumn{4}{|l|}{ Farming experience } \\
\hline$\leq 10$ & 9 & 9.9 & \multirow[t]{4}{*}{$25(1.08)$} \\
\hline $11-20$ & 34 & 37.4 & \\
\hline $21-30$ & 26 & 28.6 & \\
\hline$>30$ & 22 & 24.1 & \\
\hline \multicolumn{4}{|l|}{ Farm size (hectares) } \\
\hline$<0.99$ & 20 & 22.0 & \multirow[t]{6}{*}{$0.97(0.87)$} \\
\hline $1.00-1.99$ & 32 & 35.2 & \\
\hline $2.00-2.99$ & 18 & 19.8 & \\
\hline $3.00-3.99$ & 3 & 3.3 & \\
\hline $4.00-4.99$ & 13 & 14.5 & \\
\hline$>4.99$ & 5 & 5.5 & \\
\hline
\end{tabular}

Source: Authors' own editing, 2015

\section{Estimation of malaria cost both direct and indirect}

The following are the mean of the of the direct and indirect cost of malaria, according to Alaba(2005),direct cost of malaria include the out-of-pocket expenditures on treatment, and cost of transportation (round-trip) associated with receiving medical care. In this case, treatment costs include expenses on consultation (including laboratory test where relevant) and purchase of drugs. Table 2, 3, and 4 shows the estimation of the mean direct cost, mean indirect cost and total cost of malaria are found to be $8649.04,81094.32$ and 89743.36 respectively.

Table 2: Estimation of malaria mean direct cost 


\begin{tabular}{|l|c|}
\hline Direct cost & Mean amount(Nigerian Naira) \\
\hline Transport cost & 601.13 \\
\hline Herb cost & 2110.92 \\
\hline Drug cost & 5936.98 \\
\hline Mean direct cost & 8649.04 \\
\hline
\end{tabular}

Source: Authors' own editing, 2015

Table 3: Estimation of malaria mean indirect cost

\begin{tabular}{|l|l|}
\hline Indirect cost & Mean amount(Nigerian Naira) \\
\hline Cost of hired labor & 81094.32 \\
\hline Total indirect cost & 81094.32 \\
\hline
\end{tabular}

Source: Authors' own editing, 2015

Table 4: Estimation of the mean total cost of malaria

\begin{tabular}{|l|l|}
\hline Malaria cost & Mean amount(Nigerian Naira) \\
\hline Direct cost & 8649.04 \\
\hline Indirect cost & 81094.32 \\
\hline Total cost & 89743.36 \\
\hline
\end{tabular}

Source: Authors' own editing, 2015

\section{Regression Analysis of effects of Malaria on agricultural productivity}

For the regression analysis, linear functional form gave the best fit and was chosen as the best functional form that explains the causal relationship between productivity proxy (total productivity index) and malaria prevalence, also proxy by the frequency of malaria occurrences. Based on the consideration of statistical and economic criteria the results are presented below, the R-squared value is 0.6409 , showing that 60.90 percent of the variation in the dependent variable can be explained by the explanatory variables. This also shows that the model is a good fit for the data. Malaria prevalence, household size, farming experience and cost of malaria treatment are found to be statistically significance as a factor affecting the productivity of arable crop farmers.

Malaria prevalence was found to be significant at 5 percent with negative relationship with the productivity of the crop farmers. The estimate revealed that a unit increase in the prevalence of malaria decreases the productivity of the crop farmers by $89 \%$. This is consistent with the findings of Ajani and Ashagidigbi in year 2008.

In relation to the household size, it was found to be significant at 5 percent but positive. Large household sizes are good source of family labor which tends to enhance productivity. Thus, a unit increase in the size of the crop farmers leads to 34.4 percent increase in the productivity. The finding is in contrast to the findings of Oluwatayo (2014).

Farming experience tends to be a key instrument in attaining goals and objectives of an enterprise. Farming experience was found to be significant and had a positive relationship. This implies that as the crop farmers engages more in farming activities, the more the productivity growth. Thus, from the study, a unit increase in the experience of the crop farmers leads to 12.3 percent increase in the productivity.

Cost of malaria treatment was found to be significant and negatively impacted productivity of the crop farmers as expected. Thus, a unit naira increase in the cost of treating malaria, 
productivity of the crop farmers decreases by 59.8 percent. This implies that cost of treating malaria among the crop farmers tends to be an economic burden and have widely reduces efficiency of the crop farmers as there will be unproductive income diversification in which resources are diverted to treating the endemics disease.

Table 6: Regression analysis of impact of malaria on crop productivity of rural farmers

\begin{tabular}{|l|l|l|}
\hline Variables & Coefficient & t-statistics \\
\hline Malaria prevalence & $-0.890^{* *}$ & 2.39 \\
\hline Cost of malaria treatment & $-0.598^{*}$ & 2.89 \\
\hline Household size & $0.344^{* *}$ & 2.15 \\
\hline Farm size & 0.234 & 0.99 \\
\hline Farming experience & $0.123^{* * *}$ & 1.79 \\
\hline Age & 0.322 & 0.32 \\
\hline Constant & $2.529^{*}$ & 5.67 \\
\hline $\begin{array}{l}R^{2}=0.6709 \\
\text { Adjusted } R^{2}=0.6090\end{array}$ & \\
\hline
\end{tabular}

$*=$ Statistically significant at 1 percent level

$* *=$ Statistically significant at 5 percent level

$* * *=$ Statistically significant at 10 percent level

Source: Authors' own editing, 2015

\section{Conclusion}

Good health is an asset for agriculture, as healthy people can produce more and good nutrition contributes to it. Conversely, agriculture is an asset which contributes to good health, nutrition and resilience. When disease afflicts farmers or health of the farmers is hampered, agricultural productivity is reduced and this results into rising poverty. All of these responses can have adverse effects on the long-term labor productivity of farmers. Malaria is both a health and economic problem eating deeply into the financial base of the victims or the caregivers. Malaria has become a menace in Africa, especially in rural areas because of low level of awareness and use of modern preventive measures against mosquitoes that causes malaria. Apart from this, large household size, which is a common feature of rural people, has been a cause of increase in malaria incidence. This study focused on investigating effect of malaria on arable crop farmers' productivity. The study found that malaria is a key health concern for many households in Osun State Nigeria. Malaria being a predominant cause of illness among rural farmers therefore causes a major drawback in labour supply and eventually agricultural production. The number of workday lost as a result of malaria illness poses a very serious threat to farmers' efficiency. Also the direct and indirect cost of malaria tend to adversely affects productivity.

Based on the findings of this study, the following recommendations are proffered:

- There should be interventions in form of mobilizing resources, formulating and implementing policies and programmes that will promote awareness and measures that ensure effective prevention and control of the pandemic disease.

- Hospitals and clinics should also be easily accessible, readily available and affordable to the farmers in order to meet their health needs.

- Medication that can reduce the days of incapacitation should be intensified and made available to farmers at affordable prices in order to improve the quality of life and productivity of farmers

\section{References}


1. Ajani, O.I.Y and W.M. Ashagidigbi (2008) Effect of Malaria on Rural Households' Farm Income in Oyo State. Nigeria. African Journal of Biomedical Research, Vol. 11 (2008); 259 - 265 ISSN 1119 - 5096 (C) Ibadan Biomedical Communications Group http://dx.doi.org/10.4314/ajbr.v11i3.50723

2. Alaba, O.A. and Alaba, O. B. (2010). "Malaria in Children; Implications for the productivity of female caregivers in Nigeria". Proceeding of Annual Conference of the Nigerian Economic Society (NES), pp 395-413.

3. Coluzzi. M. (1999): "The Clay feet of the malaria giant and its African roots: hypotheses and inferences about origin, spread and control of plasmodium falciparum". Parasitologia. 41: 277-283.

4. Eyo, E.O., Ele, I. E. Eyo, O.I. (2006): Occupational Health Problems, cited in Ogana M. U. (2010): Effect of Malaria attack on income and productivity loss among Artisanal Fisher-folk in Lake Ona.

5. FAO (Food and Agriculture Organization of the United Nations) (2010). "Towards Sustainable Food Security. FAO Report on Women and Sustainable Food Security in Nigeria.

6. Google Earth (2015). Available at https://www.google.com/earth/. Retrieved on March 30, 2015.

7. Kwadwo Asenso-Okyere, Felix A. Asante, Jifar Tarekegn, and Kwaw S. Andam (2011). "Addressing the link between Agriculture, Malaria and Development in Nigeria" Conference paper for Levering Agriculture for improving nutrition and health. Pg 16.

8. Mills, A. (1998): Operational Research on the Economics of Insecticide Treated mosquito nets: Lesson of Experience. Annals of Tropical Medicine and Parasitology 92(4).

9. Neszmélyi, Gy. (2014.): The Motivations for the Diversification of the Nigerian Economy Focusing on Sustainable Agriculture. Applied Studies in Agribusiness And Commerce. HU-ISSN 1789-221X - Electronic Version: ISSN 1789-7874. Vol. 8. Number 1 of 2014. $5-11 \mathrm{p}$

10. Oluwatayo I. B. (2014) Socioeconomic Burden of Malaria on Productivity of Rice Farmers in Rural Southwest, Nigeria Mediterranean Journal of Social Sciences MCSER Publishing, Rome-Italy Vol 5 No $15 \quad$ July 2014 http://dx.doi.org/10.5901/mjss.2014.v5n15p175

11. Sachs J and P. Malaney (2010). The Economic and Social Burden of Malaria. Insight Review Articles. Center for International Development, John F. Kennedy School of Government, Harvard University.

12. Todaro, M. P. (2000). Economic Development, 7th ed. New York: Addison-Wesley Longman.

13. World Health Organization (2010). "Economic Costs of Malaria." 2001-2010 United Nations Decade to Roll Back Malaria. Accessed December 2, 2014 http://rbm.who.int/cmc upload/0/000/015/363/RBMInfosheet 10.htm.

14. World Health Organization (2011): Malaria Desk Situation Analysis-Nigeria. WHO World Malaria Report 2005.120p 